\title{
Emotional Intelligence, Self-efficacy and Occupational Stress of Academic Personnel
}

\author{
Mary Rachelle R Wapaño, $\mathrm{PhD}$ \\ Kinaadman Research Center, Xavier University - Ateneo de Cagayan, Philippines
}

\begin{abstract}
Stress in the university has a wide-ranging and negative impact on the well-being of a teacher and his or her day-to-day functioning. This is evident in many aspects: physical, psychological, cognitive, and behavioral aspects of functioning. This study examined the combined effects of emotional intelligence and self-efficacy on occupational stress; the relative contribution of emotional intelligence and self-efficacy to occupational stress; and the effect of self-efficacy on the relationship of emotional intelligence and occupational stress. Emotional intelligence is a cross section of inter-related emotional and social competencies, skills, and factors that determine how effectively a person understands and express him/herself, understand others and relate with them and cope with daily demands. Self-efficacy is the belief that one can perform a novel or difficult tasks, or cope with adversity -- in various domains of human functioning. Occupational stress, the physical, mental and emotional wear and tear brought about by incongruence between the requirement of the job and the capabilities, resources and needs of the employee to cope with job demands.
\end{abstract}

This study is a descriptive-correlational study. The results showed consistency with the research hypothesis: EI and selfefficacy has combined effect on occupational stress. The results showed a negative significant correlation between EI and stress, and between self-efficacy and stress. Self-efficacy was found to predict significantly occupational stress, but emotional intelligence did not contribute independently to the prediction of stress. This study demonstrated the mediating effect of selfefficacy on the association of EI and occupational stress. The understanding of the role of emotional intelligence and selfefficacy in teacher stress may lead to preventive intervention efforts to enhance teacher EI and self-efficacy to effectively deal with stress of academic life.

Key words: emotional intelligence, self-efficacy to occupational stress

\section{INTRODUCTION}

A $\mathrm{S}$ an academic organization, the mission of Xavier University is to form "men and women with competence, conscience, compassion and commitment." The extent to which this mission is achieved depends largely on its academic workforce, the teachers: The academic staff is crucial in the achievement of this most-important university objective.

The daily academic enterprise is placed on the proverbial shoulders of teachers. Studies have consistently shown that occupational stress experienced by university teachers is considered to be cardinal against their well-being and effective performance. Hochschild (1983), and Isenbarger and Zembylas (2006) described teaching as a form of emotional labor where feelings are constantly managed to create a public display of affection and concern. Emotional labor is thought to be a commodity that is sold for a wage and therefore has value for exchange. Inherent in emotional labor is the dissonance between real feelings and expected feeling, which in turn is detrimental to mental health. Teaching demands that teachers act as mentor, adviser and motivator and are expected to display constantly love and kindness.

There is evidence that academic workforce of higher education institutions are a particularly vulnerable occupational group (Blix \& Cruise, 1994, Watts \& Robertson, 2011). They report that the stress experienced by the academic staff is related to limited resources, shortage of time; slow progress in career advancement, and poor communication and inadequate salaries.

Additional sources of academic pressure include heavy workload, role ambiguity, conflicting job demands, frequent interruptions, and publication efforts.

Another major source of stress among university teachers is the increase of class size. Whereas in the past, teachers hold a class of an average of 35, in these days, the average class size is around 45. Student numbers have increased over the past few years and its natural consequence is the increase in teaching workload.

Gillespie, Walsh, Winefield, Dua, and Stough (2001) identified five major sources of stress in university-teaching: insufficient funding and resources, work overload, poor management practice, and insufficient recognition and reward.

Stress in the university has a wide-ranging and negative impact on the well-being of a teacher and his or her day-today functioning. This is evident in many aspects: physical, (e.g. exhaustion, headaches, high blood pressure), psychological (e.g. depression, anxiety, low self-esteem), cognitive (e.g. absent-mindedness, failure of attention and memory), and behaviofal (e.g. absenteeism, substance abuse, aggressive behavior).

Studies have shown that a teacher who possesses emotional competencies perform better in overall teaching effectiveness, understand the special needs of students, and create a caring learning environment (Fei Fei, n.d., Gay, 2010). Evidence from Chan's study (2008) also points to emotional 
intelligence as a contributing factor to effective coping with teaching-related stress.

On the other hand, self-efficacy has shown to be a protective factor among teachers against stress (Chan, 2002) while other studies found out that lower teacher self-efficacy preceded burn out (Schwarzer \& Hallum, 2008).

The consequences of teachers stress are serious. From the institution's point of view there may be significant losses of experienced and competent teachers, and those who chose to stay may become less effective, less responsive to students. In individual terms, the cost of teacher stress may include decreased self-confidence and self-esteem, and damaged personal relationships and poor health.

Teacher stress takes its toll on the personal and psychoemotional well-being of teachers. The relationship between teacher stress and teacher performance is firmly established by research (Blasé, 1986, Collie \& Perry, 2012). This is supported by Travers (2017) who maintained that teaching is recognized as one of the most stressful of all occupations and that prevalence of stress among teachers imply that the demands in teaching are mounting.

To approximate Xavier's aim of holistic development of its students, there is a need to understand teachers' experience of stress and their ability to adapt to personal changes, challenges and academic demands; and the role of emotional intelligence and self-efficacy to teacher stress.

The understanding of the role of emotional intelligence and self-efficacy in teacher stress may lead to preventive intervention efforts to enhance teacher EI and self-efficacy to effectively deal with stress of academic life.

This study then seeks to examine these issues: (1) what are the effects of emotional intelligence and self-efficacy to occupational stress among college teachers in Xavier University, and (2) what is the effect of self-efficacy on the relationship of emotional intelligence and occupational stress.

\section{REVIEW OF LITERATURE}

The variables of the study and their relationships are described and discussed below:

\section{Occupational Stress}

It has long been recognized that stress is an unavoidable characteristic of life and work. In 1956, Hans Selye, pioneer on stress studies, defined stress as a generalized non-specific response of the body to any demand made on it. Selye proposed that there are three responses to stress: alarm reaction, the immediate set of reactions to combat stress; resistance which involves adaptation to stress and exhaustion happens when the body cannot sustain the prolonged resistance.

Occupational stress is defined as tensions a person is experiencing that is related to the person's job (McVicar, 2003 cited by Huber, 2006). Job-related stress can accumulate into levels that are too high and reach the point of exhaustion, also termed as burnout. Many changes in behavior are results of stress: restlessness, emotional outbursts, impulsive behavior, excessive eating or loss of appetite, or absence from work. Teachers under stress reported greater job dissatisfaction and expressed withdrawal from teaching, such as absenteeism, early retirement or resignation (Travers \& Cooper, 1996; Carton \& Fruchart, 2014). Work-related stress can have an extensive and negative impact on the well-being of individual teacher and on his or her daily adjustments.

Some physical symptoms of occupational stress include exhaustion, headaches and high blood pressure; psychological indicators may include depression, anxiety and low selfesteem. Other symptoms also include substance abuse, aggressive behavior; and absent-mindedness, failure of attention and poor memory are cognitive signs of work stress.

It has been recognized that occupations that involve personal interactions are more susceptible to stress and burnout than those which do not require personal interactions, such as that of manufacturing. Studies also support that those in the teaching profession report that high levels of stress, which often manifest themselves as exhaustion, anxiety, depression, irritability and increased levels of stress-related illness (Winfield,2000) . Archiborg and Effiom (2010) indicate that career development is identified as a major source of stress.

Studies indicated that the prevalence of occupational stress among university academic staff is increasing across countries and is alarmingly pervasive (Boyd and Wylie, 1994, Mark \& Smith, 2012). Other research results indicated that teachers expressed exhaustion and burnout due to increasing workload. From the standpoint of the organization, there are tangible financial costs of occupational stress.

It has been reported that a significant fraction of absenteeism, staff turnover, injuries, low morale and low productivity among university teachers can be attributed to job stress (Cooper \& Cartwright, 1994, Ejere, 2010).

These studies demonstrate the prevalence of stress among university teachers, and its negative collective effect on the academic organization and individual impact on the well being of teacher.

\section{Self-Efficacy}

Self-efficacy is one of two variables whose contribution to occupational stress was investigated in this study. Perceived self-efficacy is described as a person's beliefs about his capabilities to produce a certain level of performance that exercise influence over events that affect his life (Bandura, 1998). Individuals with high self-efficacy approach difficult tasks as challenges to be measured rather than as threats to be avoided. They approach threatening situation with assurance that they can exercise control over them. Such an efficacious outlook produces personal accomplishment, reduces stress and lowers vulnerability to depression. 
A strong self-efficacy enhances human accomplishment and personal well-being in many ways. Efficacy beliefs influence the amount of stress and anxiety individual experience as they engage in an activity (Pajare, 1994; Bandura, 1997, Vaeizi \& Fallah, 2011). Self-efficacy has been widely tested in varied disciplines and other variables. Results had shown significant findings: it has been found out that self-efficacy beliefs have been found to be related to clinical problems such as addiction, depression, social skills, assertiveness, stress, pain control and health. On the other hand, people with low sense of self-efficacy tend avoid difficult tasks which they view as personal threats. They have low aspirations and weak commitment to the goals they choose to pursue. When faced with difficult tasks, they dwell on their personal deficiencies, on the obstacles they will encounter, and on all kinds of adverse outcomes rather than concentrate on how to perform successfully. (Multon, Brown and Lent, 1991; Pajare, 1996, 1997; Bandura, 2000).

Teacher self - efficacy refers to the extent to which teachers believe they can bring about change and impact on student behavior and learning outcomes (Gibson \& Dembo, 1984). Bandura (1994) observed that teachers who have a high sense of efficacy about their teaching competence can are able to encourage their students and enhance their learning. He believed that essential in creating effective learning environment is a teacher's sense of self-efficacy. Studies have established that teachers with a strong sense of efficacy tend to exhibit greater levels of planning, organization, and enthusiasm. They persist when and are more resilient in the face of setbacks, they tend to be less critical with students who make errors (Tschanhen-Moran and Woolfolk, 2001); are more humanistic in their approach to their students, have creative lesson presentation and excellent questioning skills, have more effective classroom organization strategies, (Emmer \& Hickman, 1991; Saklofske, et al, 1988); are more likely to learn and use new approaches and strategies for teaching, provide special assistance to low achieving students, and persist in the face of student failure (Ross, 1994)

These studies show that teacher self efficacy is important in to student achievement, classroom atmosphere and health of the organization. In this study, the role of self-efficacy is examined as a predictor to teacher stress.

\section{Emotional Intelligence}

The beginnings of the EI theory can be traced back to E.L. Thorndike in 1920 who formulated the concept of "social intelligence." For Thorndike, social intelligence is the "ability to understand and manage men and women, boys and girls, to act wisely in human relations." (p.228). The concept of social intelligence has evolved since.

Gardner (1983), building on Thorndike's work, developed the theory of multiple intelligences. He classified intelligence into two categories: interpersonal intelligence the ability to understand other people, what motivates them, how they work, and how to work cooperatively with them; and intrapersonal intelligences, the understanding of dynamics of oneself and using this understanding to live effectively and meaningfully.

Salovey and Mayer (1990) coined the term "emotional intelligence" which they theorized as a subscale of social intelligence that involves the ability to monitoring, discriminating and using one's emotions to think and behave productively. Inherent in this definition of emotional intelligence is the accurate perception and positive expression of emotion. They also proposed that EI is the ability to generate emotional knowledge, regulate one's emotions to promote psychoemotional growth. Goleman (1995) proposed that EQ is equal to, if not more important than IQ, in predicting professional and personal success and that emotional intelligence can affect significantly the individual work situation and the organizational dynamics.

Bar-On (2005) proposed a new model of emotional intelligence: In Bar-On's model emotional intelligence is thought to be a cross section of inter-related emotional skills and social competencies that determine how effectively we understand and express ourselves, understand others and relate with them and cope with daily demands.

This model of emotional intelligence bears some similar components with the previous EQ theories which includes: the ability to recognize, understand, and express emotions, the ability to understand how others feel and relate with them, the ability to manage and control emotion; the ability to manage change, adapt, and solve problems of a personal and interpersonal nature and the ability to generate positive effects and be self-motivated.

According to the Bar-On model, emotional social-intelligence is a "cross-section of interrelated emotional and social competencies, skills and facilitators that determine how we understand and express ourselves, understand others and relate with them, and cope with daily demand, challenges and pressures." (BarOn, 2005).

In this model, five meta factors are identified: intrapersonal factor, which involves self-awareness and self-expression; interpersonal factor, which involves social awareness and quality of interaction; stress management, which includes emotional management and control; adaptability, referred to the ability to manage change; and general mood which involves motivation.

\section{Emotional Intelligence and Self-Efficacy}

Recent studies point to the relationship of emotional intelligence and self-efficacy.

Rathi and Rastogi (2008) found that emotional intelligence to have a positive relationship with occupational self-efficacy, and is found to be one of the significant predictors occupational efficacy. This study showed that with workers higher emotional intelligence are more effective employees than their counterparts with lower emotional intelligence. 
Chan (2004) found that certain components of emotional intelligence predict self-efficacy among teachers: positive regulation of emotion is found to predict general self-efficacy, and empathic sensitivity emerged as a significant predictor in self-efficacy toward helping others. Similarly, DiFabio and Palazzeschi (2008) found a relationship between EI and occupational self-efficacy: specifically, teacher self-efficacy was found to be related to the intrapersonal dimension of EI.

Penrose, Perry and Ball (2007) have demonstrated the significant relationship between levels of emotional intelligence in teachers, their self-efficacy and teacher effectiveness. Eissa and Khalifa (2008) postulated that job stress is a major factor that adversely impacts a teacher's wellbeing and presented findings of the interactive and relative effects of emotional intelligence and self-efficacy. Recent studies such as the study of Sahin (2017) reported that teacher self-efficacy is related to teachers' or pre-service teachers' feelings of competence in their profession.

These studies show evidence of the relationship of emotional intelligence and self-efficacy. In this study, emotional intelligence and self-efficacy are used as predictor variables to occupational stress of teachers.

\section{Emotional Intelligence and Occupational Stress}

The study of Jacob, Kemp and Mitchell (2008) who examined the elements of emotional-social intelligence found that teachers with low self- and social-awareness, tended to have insufficient self-management skills. This study indicated a need to create mechanisms through which teachers can effectively learn self- and social-awareness.

Gardner and Stough (2003) hypothesized that EI is related to respondents' ability to manage stress and physical and psychological health. Regression analysis results showed emotional management and emotional control were important predictors of occupational stress. This evidence led to the conclusion that the ability to deal with emotions and emotional information in the workplace helps employees in managing stress in the workplace and in maintaining psychological well-being.

Research of Olivier (2005) indicated that people in the teaching professions are particularly vulnerable to emotional distress. Results from Jordan, Ashkanasy and Hartel (2002) points to the moderating effect of emotional intelligence to emotional reactions to job insecurity and their ability to cope with stress, that is, respondents with low emotional intelligence are more likely than respondents with high emotional intelligence to experience negative emotional reactions to job insecurity and to use negative coping strategies. Merida-Lopez, Extremera, and Ray (2017) revealed in their study the additive and interactive effects of role stress and emotional intelligence for predicting engagement. They have found that emotional intelligence and engagement were positively associated, and that the interaction of role ambiguity and emotional intelligence was significant in explaining engagement dimensions. They have found that emotional intelligence boosted engagement when the levels of role ambiguity were higher.

These results collectively confirm the hypothesis of the present study that emotional intelligence is related to occupational stress.

\section{Self-Efficacy and Occupational Stress}

Studies on self- efficacy and occupational stress revealed significant relationship. Jex and Gudanowski (2002) investigated the role of self-efficacy in the stress process by examining relationships between stressors identified as role ambiguity, situational constraints and hours; strains identified as job dissatisfaction, anxiety, frustration and turnover intent; and efficacy beliefs, both individual and collective. This study's results revealed individual efficacy to be related to some strains and had no mediating or moderating effects. On the other hand, collective efficacy is found to be strongly related to both stressors and strains. Collective efficacy moderated the effect of work hours and mediated the relationship between situational constraints and some strains.

Teacher self-efficacy was studied as a personal resource factor that may protect from the experience of job strain. Schwarzer and Hallum (2008) examined the relationship between selfefficacy, job stress and burnout. This study's results showed the mediating effect of self-efficacy on stress and burnout specific to younger teachers with low general self-efficacy.

The longitudinal study which employed structural equation models showed that low self-efficacy preceded burnout. This study recommended further research on the mechanisms of teacher self-efficacy and stress by interventions that aim at strengthening teacher self-efficacy as a protective resource factor

\section{Mediating effect of Self-efficacy}

There is a dearth in the literature on the mediating effect of self-efficacy on motional intelligence and occupational stress. The related study of Brown and Schutte (2009), however, found that higher emotional intelligence is associated with less fatigue. Their results also showed that the relationship between EI and fatigue is partially mediated by psychosocial variables as depression, anxiety, optimism, internal health, locus of control, amount of social support, and satisfaction with social support.

As the previous studies had presented, there is an established relationship between emotional intelligence and self-efficacy. Literature has also presented a relationship between emotional intelligence and occupational stress as well as self-efficacy and occupational stress. There is little in the literature that explored the mediating effect of self-efficacy on emotional intelligence and stress.

This study attempts to examine two research issues: (1) the contribution of emotional intelligence and self-efficacy to 
teacher stress, as well as (2) the effect of self-efficacy on the association of emotional intelligence and stress.

\section{DEFINITION OF TERMS}

The present study examines the interactive and relative contribution of predictor variables, emotional intelligence and self-efficacy, to criterion variable occupational stress, as well as the mediating effect of self-efficacy on the link between emotional intelligence and occupational stress.

In this study, emotional intelligence is defined as a cross section of inter-related emotional and social competencies, skills, and factors that determine how effectively one understand and express oneself, understand others and relate with them and cope with daily demands and is measured by Bar-On Emotional Quotient Inventory: Short Version (BarOn EQ-i).

Self-efficacy is defined in this study as the belief that one can perform a novel or difficult tasks, or cope with adversity -- in various domains of human functioning. Perceived selfefficacy facilitates goal-setting, effort investment, persistence in face of barriers and recovery from setbacks. This is measured in this study General Perceived Self-efficacy Scale (GPSS).

Occupational stress, is defined, in this study as the physical, mental and emotional wear and tear brought about by incongruence between the requirement of the job and the capabilities, resources and needs of the employee to cope with job demands and is measured by Occupational Stress Scale (OSS).

The following research questions are addressed in this study:

1.intelligence and self-efficacy on occupational stress?

2. What is the relative contribution of emotional What are the combined effects of emotional intelligence and self-efficacy to occupational stress?

3. What is the effect of self-efficacy on the relationship of emotional intelligence and occupational stress?

This study tested the following hypotheses:

Hypothesis 1: Emotional intelligence and self-efficacy has a combined effect on occupational stress.

Hypothesis 2: Emotional intelligence and self-efficacy has relative effect on occupational stress.

Hypothesis 3: Self-efficacy mediates on the relationship between emotional intelligence and occupational stress.

The results of this study will be beneficial for college teachers in understanding the role of emotional intelligence and selfefficacy in occupational stress: how emotions play a role in managing work-related stress. By understanding the role of emotional intelligence and self-efficacy to teacher stress, perhaps the ways in which teachers can learn to cope with challenging and adverse situations. The results of this research may be validation for developing teachers' emotional competencies to reduce negative affective outcomes. This study is a significant endeavor in managing occupational stress among teachers by promoting emotional competencies and developing emotional intelligence and self-efficacy. University administrators may become aware of the impact of emotional competencies of teachers to their ability to manage stress and adverse situations in the university. This study may provide University administrators relevant information into the teachers' emotional competencies, their experience of stress and their ability to deal with challenging situations within the university and in their personal-family life.

The results may encourage University administrators to establish policies or programs geared towards developing teachers' emotional competencies and resilience. It will serve as future reference for researchers who will want to examine the emotional competencies of teachers from other levels: in the grade school or high school; for researchers who will want to examine the emotional competencies of teachers from the public schools or state university. Finally, this study will hopefully be of value to faculty development programs: to include, not only programs for professional advancement and growth, but the learning and development of emotional competencies.

\section{RESEARCH DESIGN AND METHODS}

\section{Design}

The present study is a descriptive-correlational study. It will examine the effect of emotional intelligence and self-efficacy on occupational stress, and the effect of self-efficacy on the relationship between emotional intelligence and stress.

\section{Participants}

The respondents for this study were from college faculty for SY 2007-08. The pool of respondents includes regular and on-probation full-time college teachers from the different colleges: arts and sciences, nursing, accountancy, agriculture, education, and vocational center for industrial technology. There were 48 respondents for this study. This number of participants is largely due to pragmatic considerations, as the purchase of Bar-On questionnaire had proven to be costly. The standard rule of thumb for sampling for these kinds of studies was adapted: to have at least 10 data per explanatory or independent variable. In this study, there are two explanatory variables in this study, namely emotional intelligence and self-efficacy. The 48 sample size may suffice following this rule of thumb. Future similar research may have to reconsider to increase this sample size.

\section{Ethical Considerations}

Official permission to conduct the study from the Deans were sought. of the

Individual informed consent was obtained from each participant with explanation of the study objectives and procedures. Participants were reassured that participation 
istotally voluntary, that the information provided by them are confidential

\section{Materials}

For this study, four measures were used in this study.

The Generalized Perceived Self-Efficacy Scale (GPSS) is a 10 -item psychometric scale that is designed to assess optimistic self-beliefs to cope with a variety of difficult demands in life. The scale has been originally developed in German by Matthias Jerusalem and Ralf Schwarzer (1981). In samples from 23 nations, Cronbach's alpha ranged from .76 to .90 , with the majority in the high .80 s. The response scores were summed up to all 10 items to yield the final composite score with a range from 10 to 40 with low scores suggesting weak beliefs in one's ability to perform difficult tasks and high scores indicating strong belief in one's capacity. An umbrella permission is granted in using and reproducing this measure in research studies as long as the source of the scale is properly recognize. Source of scale is recognized in this study in the references.

The Occupational Stress Scale (OSS) developed by House, McMichael, Wells, Kaplan and Landerman (1979) measures a variety of stressful job situations. The measure has five subscales that assess the extent of occupational stress due to job responsibilities, quality concern, role conflict, job and non-job conflict and workload. Coefficient alpha values ranged .59 to .76 for responsibility pressure, .56 to .76 for job versus non-job conflict. Alpha for quality concerns was .72, for role conflict was .70 and for workload stress was .73. (House et al., 1979, cited by Fields, 2002). The 10-item statements using a five-point scale ranging from 1 (never like me) to 5 (always like me). At the time of this research, this measure was in the public domain and with implicit permission.

Emotional intelligence was measured by means of the Bar-On Emotional Quotient Inventory: Short Version (BarOn EQ-i:) . This is a 51-item instrument which assesses the key aspects that define emotionally intelligent behavior: intrapersonal, interpersonal, stress management, adaptability and general mood. This tool uses a five-point Likert-style response format in which respondents are asked to rate each statement with respect to their own experience. The response options are "very seldom or not true of me," "seldom true of me," "sometimes true of me," "often true of me," "very often true of me or true of me." Scores above 130 indicate a welldeveloped emotional and social capacity and scores 80 suggest an underdeveloped emotional and social competency as well as considerable room for improvement. Internal consistency coefficients ranged from .76 to .93 (BarOn, 2002). This test was purchased for the purpose of measuring research variable EI.

\section{Procedure}

The four instruments were administered to the college teachers involved in this study by the researcher and a research assistant. The consent of the teachers were obtained and the purpose of the study was explained before distributing the instruments. Retrieved measures where encoded and analyzed.

\section{Data Analysis}

To assess the relationship between emotional intelligence and self-efficacy with occupational stress, multiple regression analysis will be performed. To assess the effect of selfefficacy on the relationship between emotional intelligence and occupational stress, mediation analysis was performed.

\section{LIMITATIONS OF THE STUDY}

There are some limitations that need to be acknowledged in the present study: The first limitation is concerned with this study's reliance on self-report measures which focuses on the individual's stated self-beliefs, which may not encompass the entire range of emotional competencies, psychological distress or psychological health.

The second limitation is concerned with causality, as the present study is correlational in nature, the direction of causality then cannot be determined.

Sample size was limited by the number of copies of the BarOn Short-Version Inventory acquired. This is a practical limitation in that the Bar -On questionnaires had proven to be costly.

\section{RESULTS}

Three issues were addressed by the present study: Firstly, to examine the contribution of emotional intelligence and selfefficacy to the prediction of stress of XU college teacher. Secondly, this study also examines the relative contribution of EI and self-efficacy to occupational stress. Last, the present study addressed the issue of the mediating effect of selfefficacy on emotional intelligence and occupational stress.

The results of the data analysis are presented below.

\section{Contribution of EI and Self-efficacy to Occupational Stress}

Table 1 shows the multiple regression analysis between predictor variables emotional intelligence and self-efficacy and criterion variable, occupational stress. The results show that emotional intelligence and self-efficacy when combined generated a coefficient of multiple regression $\mathrm{R}$ of .535 and a multiple correlation square of .287 .

This shows that 28.7 per cent of the total variance in occupational stress is accounted for by the combinations of emotional intelligence and self-efficacy.

The same table also indicates that the analysis of variance of the multiple regression data produced an F-ratio value significant at 0.01 level, $F(2,45)=9.039, \mathrm{p}<.001$ attests that the predictive capacity of the independent variables cannot be attributed to chance factors. 
Table 1

Summary of Multiple Regression Analysis between the Predictor Variables (Emotional Intelligence and Self-efficacy) and the Outcome Variable (Occupational Stress)

\begin{tabular}{|c|c|c|c|c|}
\hline \multicolumn{5}{|c|}{$\begin{array}{c}\text { Multiple R (Adjusted) }=.535 \\
\text { Multiple R } \text { R }^{2} \text { (Adjusted) }=.287 \\
\text { Stand error estimate }=.362007\end{array}$} \\
\hline Source of variation & $\begin{array}{c}\text { Sum of } \\
\text { squares }\end{array}$ & df & $\begin{array}{c}\text { Mean } \\
\text { Square }\end{array}$ & F ratio \\
\hline Regression & 2.369 & 2 & 1.185 & $9.039^{* *}$ \\
\hline Residual & 5.987 & 45 & .131 & \\
\hline Total & 8.8266 & 47 & & \\
\hline $\mathrm{p}<.01$ & &
\end{tabular}

Relative contribution of EI and self-efficacy to occupational stress

From the results displayed on table 2, independent variable self-efficacy, $\mathrm{t}(45)=-3.342, \mathrm{p}<.05$ made a significant contribution to the prediction of occupational stress. However, emotional intelligence, $\mathrm{t}(45)=.035, \mathrm{p}=.835$, did not. The relationship between self-efficacy and occupational stress is negative: as self-efficacy increases, occupational stress decreases.

Table 2

Relative Contribution of the Independent Variables to the Prediction of Occupational Stress

\begin{tabular}{|c|c|c|c|}
\hline Predictor & B & SE b & $\beta$ \\
\hline Constant & 4.826 & .565 & \\
\hline Emotional intelligence & .001 & .005 & .035 \\
\hline Self-efficacy & -.074 & .022 & $-.558^{*}$ \\
\hline
\end{tabular}

$* \mathrm{p}<.05$

\section{Mediating effect of self-efficacy on EI and occupational stress}

The present study also examined the mediating effect of selfefficacy on the relationship between emotional intelligence and occupational stress. All three correlations among the three variables are statistically significant.

Table 3 shows the correlation coefficients of the variables. There is strong, positive significant relationship between the two predictor variables, emotional intelligence and selfefficacy $(r=.656)$. The results revealed a moderate, significant, negative relationship between emotional intelligence and occupational stress $(r=-.331)$. There is a strong, significant, negative correlation between self-efficacy and occupational stress $(\mathrm{r}=-.535)$.

Table 3 Correlations between Variables

\begin{tabular}{|c|c|c|}
\hline Variables & Self-efficacy & Occupational stress \\
\hline Emotional intelligence & $.656^{*}$ & $-.331^{*}$ \\
\hline Self efficacy & - & $-.535^{*}$ \\
\hline
\end{tabular}

Table 4 shows the $\beta$ value and standard error when was selfefficacy was regressed on emotional intelligence. Analysis yielded a $\beta$ value of .656 and standard error of .024.

Table 4

Multiple Regression Analysis between Emotional intelligence and Selfefficacy

\begin{tabular}{|l|l|l|l|}
\hline Predictor & B & SE b & $\beta$ \\
\hline Constant & 20.634 & 2.227 & \\
\hline $\begin{array}{l}\text { Emotional } \\
\text { intelligence }\end{array}$ & .139 & .024 & .656 \\
\hline $\mathrm{p}<.05$ & & & \\
\hline
\end{tabular}

As shown in table 2, when occupational stress was regressed on emotional intelligence and self-efficacy, the $\beta$ value is -.558 with standard error .022 ; and the $\beta$ value for emotional intelligence is .035 .

Mediation analysis yielded significant mediation of selfefficacy on the relationship between emotional intelligence and occupational stress, with Sobel's z-value $=-2.909, \mathrm{p}<$ .05. The correlation between emotional intelligence and occupation stress became non-significant in the second regression, thus full mediation is identified.

The association between emotional intelligence and occupational stress has been significantly reduced by the inclusion of the self-efficacy in the second regression. The indirect effect $(-.366)$ to total effect $(-.331)$ ratio is 100 percent, indicating that all of the effect of emotional intelligence on occupational stress goes through self-efficacy as a mediating variable, and none of the effect of emotional intelligence to occupational stress is direct.

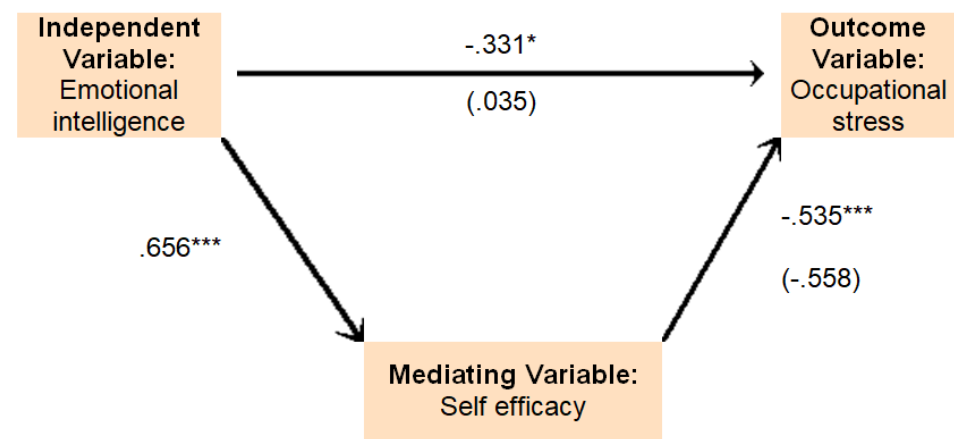

Figure 1. The Mediating effect of Self-efficacy on Emotional Intelligence and Occupational Stress

\section{DISCUSSION}

Three research issues were addressed by the present study: Firstly, to examine the contribution of emotional intelligence and self-efficacy to the prediction of stress of XU college teacher. Secondly, this study also examined the relative contribution of EI and self-efficacy to occupational stress. Last, the present study addressed the issue of the mediating effect of self-efficacy on emotional intelligence and occupational stress. 
The results of this study revealed three main findings that provided support for effect of EI and self-efficacy on occupational stress.

First, consistent with the research hypothesis, EI and selfefficacy has combined effect on occupational stress. The results also showed a negative significant correlation between EI and stress, and between self-efficacy and stress. These results appear to be natural based on the nature the constructs of emotional intelligence and self-efficacy. The EI construct allows for the understanding of one's and other's emotions and the ability to regulate and manage one's emotions; while the self-efficacy construct allows for beliefs in one's capacity to produce some levels of accomplishment. The findings

of Chan (2008) lend some support to the present finding: Certain EI dimensions and the interaction of self-efficacy to these EI dimensions predict active coping strategies. The results are consistent with other studies in that emotional intelligence and stress at work have shown to have negative correlations (Nikolau \& Tsaousis, 2002)

The study of Martinez-Monteagudo, Ingles, and Granados (2019) which sought to verify the differences between emotional intelligence profiles and burnout, anxiety, depression, and stress among teachers. Their study revealed that teachers identified to be in the generalized low emotional intelligence group and the group with high attention and low repair obtained higher scores in Emotional Exhaustion, Depersonalization, Anxiety, Depression, and Stress

Second, in this study, self-efficacy was found to predict significantly occupational stress, but emotional intelligence did not contribute independently to the prediction of stress. The findings of Schwarzer and Hallum (2008) support the results of the present study: who found that low self-efficacy preceded teacher burnout. This result is similar to the results found by Klassen and Chiu (2010) who showed that teachers who experience more demands in the classroom reported lower self-efficacy and lower job satisfaction. Recent study by Troesch and Bauer (2017) also showed negative relationship between self efficacy and stress among second career teachers. Their study revealed that self-efficacy has higher impact on job stress for second career teachers.

While some literature provides evidence of the predictive ability of EI to occupational stress, this study did not find EI to be a significant predictor of teacher stress. Other literature points to the moderating effect of EI: as in the study of Ashkanasy and Hartel (2002) who found EI as a moderating variable to to emotional reactions to job insecurity and stresscoping ability.

Lastly, the study demonstrated the mediating effect of selfefficacy on the association of EI and occupational stress. This indicates that the level of emotional intelligence affects the level of self-efficacy which in turn affects the level of occupational stress. Alternatively, it can also be said that the level of emotional intelligence affects the level of occupational stress through self-efficacy. In other studies, EI has been found to be a protective factor for teachers who are under significant occupational stress (Salami, 2010). Recent studies suggest that mediating relationships among selfefficacy, EI and performance: Udayar, Flori, and Bauserron (2020) showed that self-efficacy fully mediated the relationship between train EI and subjective and objective performance. This result suggest the contribution of EI to performance when under stress.

Although, the present study was limited by its reliance on selfreport measures which focuses on the individual's perceptions about his or her psycho-emotional states and not directly measure emotional competencies, people, in general, consistently with their expressed beliefs (Bandura, 1997). As a recommendation for future research, the number of sample size may have to be considered to represent the population.

A variety of implications emerge from the results of the present study: Under stressful situations, prevention strategies may involve the improvement of teacher's self-efficacy, through teaching training programs aimed at improving teaching efficacy. This study suggests that at certain levels of emotional intelligence and self-efficacy can help teachers cope with stressors more effectively. Enhancing both EI and teacher self-efficacy may prove beneficial to the teachers themselves, their students, and to the whole academic organization. Further research may study the interventions aimed strengthening teacher self-efficacy as a protective resource factor. The effect of specific dimensions of EI, intrapersonal, interpersonal, adaptability, general mood, to occupational stress may be examined.

\section{CONCLUSION}

This study revealed these findings that provided support for effect of EI and self-efficacy on occupational stress: The results showed that EI and self-efficacy has combined effect on occupational stress; that there is a negative significant correlation between EI and stress; and between self-efficacy and stress, self-efficacy was found to predict significantly occupational stress, but emotional intelligence did not contribute independently to the prediction of stress. The results also demonstrated the mediating effect of self-efficacy on the association of EI and occupational stress. This indicates that the level of emotional intelligence affects the level of self-efficacy which in turn may affectsthe level of occupational stress. EI has been found to be a protective factor for teachers who are under significant occupational stress (Salami, 2010)

These results may be basis for the promotion of EI and learning of emotional competencies in teaching by improving teachers' sense of self-efficacy can help them cope better with stressors. 


\section{REFERENCES}

[1] Abbott, Gypsy. (2004, March 1). A study of teacher resilience in urban schools The Free Library. (2004). Retrieved July 31, 2009 from http://www.thefreelibrary.com/A study of teacher resilience in urban schools-a0115034759

[2] Akinboye, Akinboye and Adeyemo. (2002). Emotional intelligence and self-efficacy as predictors of occupational stress among academic stag in a Nigerian University. Retrieved July 30, 2009, from http://wwwlib.murdoch.edu.au

[3] Archibong, I. A., Bassey, A. O., \& Effiom, D. O. (2010). Occupational stress sources among university academic staff. European Journal of Educational Studies, 2(3), 217-225.

[4] Atkins, P. \& Stough, C. (2005, ). Does emotional intelligence change with age? Paper presented at the Society for Research in Adult Development annual conference, Atlanta, GA.

[5] Bandura. (1977) . Self-efficacy: Towards a Unifying Theory of Behavior Change". Psychological Review 84, 191-215. Retrieved July 31, 2009, from http://www.garfield.library.upenn.edu

[6] Bar-On. (2005) . The Bar-On Model of Emotional-Social Intelligence". Retrieved July 30, 2009, from http://www.reuvenbaron.org/bar-on-model/

[7] Blasé, J. (1986). The qualitative analysis of sources of teacher stress: Consequences for performance. American Educational Research Journal, v23, p 13-40. Retrieved July 31, 2009 from http://www.eric.ed.gov

[8] Blix, Cruise, Mitchell \& Blix, 1994. "Occupational Stress Among University Teachers" Educational Research, v36, 157-169 from http://www.eric.ed.gov

[9] Boyd and Wylie. (1994). Workload and Stress in New Zealand Universities. Wellington: New Zealand Council for Educational Research and the Association of University Staff of New Zealand

[10] Brown, R. \& Schutte, N. (2009). Direct and indirect relationships between emotional intelligence and subjective fatigue in university students. Journal of Psychosomatic Research, v 60 (6), 585-593. Retrieved September 19, 2009 from http://linkinghub.elsevier.com

[11] Chan, D. (2008). Emotional intelligence, self-efficacy and coping among Chinese prospective and in-service teachers in Hongkong. Educational Psychology, v28, p397-498. Retrieved July 30, 2009 from http://www.eric.ed.gov

[12] Chan, D. (2004, June). Perceived emotional intelligence and selfefficacy among Chinese secondary school teachers in Hong Kong. Personality \& Individual Differences, 36(8), 1781. Retrieved July 31, 2009, doi:10.1016/j.paid.2003.07.007

[13] Chan, D. (2007, February). Burnout, Self-efficacy, and Successful Intelligence among Chinese Prospective and In-service School Teachers in Hong Kong. Educational Psychology, 27(1), 33-49. Retrieved July 31, 2009, doi:10.1080/01443410601061397

[14] Carton, A., \& Fruchart, E. (2014). Sources of stress, coping strategies, emotional experience: effects of the level of experience in primary school teachers in France. Educational Review, 66(2), 245-262.

[15] Ciarrochi, Chan \& Bajgar. (2001). "Measuring Emotional Intelligence in Adolescents". Personality and Individual Differences, v31, 1105-1119, from http://www.sciencedirect.com/

[16] Collie, R. J., Shapka, J. D., \& Perry, N. E. (2012). School climate and social-emotional learning: Predicting teacher stress, job satisfaction, and teaching efficacy. Journal of Educational Psychology, 104(4), 1189.

[17] Cooper and Cartwright. (1994). "Stress Management Interventions in the Workplace: Stress Counseling and Stress Audits". British Journal of Guidance and Counseling

[18] Di Fabio, A., \& Palazzeschi, L. (2008, April). Emotional intelligence and self-efficacy in the sample of highschool teachers. Social Behavior \& Personality: An International Journal, 36(3), 315-326. Retrieved July 31, 2009, doi:10.2224/sbp.2008.36.3.315

[19] Eissa, M., \& Khalifa, W. (2008). CHAPTER 5: Emotional Intelligence and Self-efficacy as Predictors of Job Stress among Elementary School Teachers in Egypt. . (pp. 77-92). Peter Lang
Publishing, Inc. Retrieved July 31, 2009, from Education Research Complete database.

[20] Ejere, E. I. (2010). Absence from work: A study of teacher absenteeism in selected public primary schools in Uyo, Nigeria. International Journal of Business and Management, 5(9), 115.

[21] Emmer, E. T. \& Hickman, J. (1991). Teacher efficacy in classroom management and discipline. Educational and Psychological Measurement, 51, 755-765.

[22] Fields, D. (2002). Taking the measure of work: A guide to validated scales for organizational research and diagnosis. Sage. Retrieved July 31, 2009, from http://books.google.com.ph

[23] Gardner. (1983). Frame of Mind: The theory of multiple intelligences. New York: Basic Books.

[24] Gardner, L., \& Stough, C. (2003, August 2). Exploration of the relationships between workplace Emotional Intelligence, occupational stress and employee health. Australian Journal of Psychology, 55, 181-181. Retrieved July 31, 2009, from Academic Source Complete database.

[25] Gay, G. (2010). Culturally responsive teaching: Theory, research, and practice. Teachers College Press

[26] Gibson, S. \& Dembo, M. (1984). Teacher efficacy: A construct validation. Journal of Educational Psychology, v31, 627-643, Retrieved July 30, 2009 from http://intl-aer.sagepub.com

[27] Goleman 1995. Goleman, D. (1998). Working with Emotional Intelligence. New York: Bantam Books

[28] Gillespie, N., Walsh, M., Winefield, A., Dua, J., \& Stough, C. (2001, January). Occupational stress in universities: staff perceptions of the causes, consequences and moderators of stress. Work \& Stress, 15(1), 53-72. Retrieved July 30, 2009, doi:10.1080/02678370110062449

[29] Hochschild. (1983). The Managed Heart: Commercialization of Human Feeling. Berkley, C.A.: University of California Press.

[30] Isenbarger, L., \& Zembylas, M. (2006). The emotional labour of caring in teaching. Teaching and teacher education, 22(1), 120134.

[31] Jacobs, S., Kemp, A., \& Mitchell, J. (2008, January). Emotional intelligence: hidden ingredient for emotional health of teachers. Africa Education Review, 5(1), 131-143. Retrieved July 31, 2009, doi:10.1080/18146620802144842

[32] Jerusalem, M., \& Schwarzer, R. (1992). Self-efficacy. Retrieved July 2009 from http://www.healthpsych.

[33] Jex, Steve M.; Bliese, Paul D. Efficacy beliefs as a moderator of the impact of work-related stressors: A multilevel study. Journal of Applied Psychology. Vol 84(3), Jun 1999, 349-361

[34] Jex, S., \& Gudanowski, D. (1992, September). Efficacy beliefs and work stress: An exploratory study. Journal of Organizational Behavior, 13(5), 509-517. Retrieved July 31, 2009, from Business Source Complete database.

[35] Jose, P. E. (2003) MedGraph-I: A programme to graphically depict mediationamong three variables: The internet version, version 2.0.Victoria Univesity of Wellington, Wellington, New Zealand. Retrieved [date] from http://www.victoria.ac.nz/staff/paul-josefiles/medgraph/medgraph.php.

[36] Jordan, P., Ashkanasy, N., \& Hartel, C. (2002, July). Emotional intelligence as a moderator of emotional and behavioral reactions to job insecurity. Academy of Management Review, 27(3), 361372. Retrieved July 31, 2009, from Business Source Complete database.

[37] Klassen, R. M., \& Chiu, M. M. (2010). Effects on teachers' selfefficacy and job satisfaction: Teacher gender, years of experience, and job stress. Journal of educational Psychology, 102(3), 741.

[38] Mark, G., \& Smith, A. P. (2012). Effects of occupational stress, job characteristics, coping, and attributional style on the mental health and job satisfaction of university employees. Anxiety, Stress \& Coping, 25(1), 63-78.

[39] Martínez-Monteagudo, M. C., Inglés, C. J., Granados, L., Aparisi, D., \& García-Fernández, J. M. (2019). Trait emotional intelligence profiles, burnout, anxiety, depression, and stress in secondary 
education teachers. Personality and Individual Differences, 142, 53-61.

[40] Mérida-López, S., Extremera, N., \& Rey, L. (2017). Contributions of work-related stress and emotional intelligence to teacher engagement: Additive and interactive effects. International journal of environmental research and public health, 14(10), 1156.

[41] Nikolaou, I., \& Tsaousis, I. (2002, October). Emotional intelligence in the workplace: Exploring its effects on occupational stress and organizational commitment. International Journal of Organizational Analysis (1993 - 2002), 10(4), 327. Retrieved July 31, 2009, from Business Source Complete database.

[42] Osborn, N. (n.d.). AQ Adversity Quotient: A complement to emotional intelligence. Retrieved July 31, 2009, from http://www.teaminternational.net

[43] Penrose, A., Perry, C. \& Ball, I. (2007). Emotional intelligence and teacher self efficacy: The contribution of teacher status and length of experience. Issues In Educational Research, 17(1), 107126. http://www.iier.org.au/iier17/penrose.html

[44] Penrose, A., Perry, C., \& Ball, I. (2007, April). Emotional intelligence and teacher self efficacy: The contribution of teacher status and length of experience. Issues in Educational Research,17(1), 107-126. Retrieved July 31, 2009, from Education Research Complete database

[45] Qing, G, \& Day, C. (2006). Teachers resilience: A necessary condition for effectiveness. Teacher and Teaching Education, v23(8), 1302-1316. Retrieved July 31, 2009 from http://www.sciencedirect.com

[46] Rathi, N., \& Rastogi, R. (2008, April). Effect of Emotional Intelligence on Occupational Self-Efficacy. ICFAI Journal of Organizational Behavior, 7(2), 46-56. Retrieved July 31, 2009, from Business Source Complete database.

[47] Ross. (1994). "Beliefs that Make a Difference. The Origins and Impacts of Teacher Efficacy". Retrieved July 30, 2009, from http://www.eric.ed.gov/

[48] Sahin, H. (2017). Emotional Intelligence and Self-Esteem as Predictors of Teacher Self-Efficacy. Educational Research and Reviews, 12(22), 1107-1111.

[49] Salami, S. O. (2010). Occupational stress and well-being: Emotional intelligence, self-efficacy, coping, negative affectivity and social support as moderators. The journal of international social research, 3(12), 387-398.

[50] Salovey and Mayer. (1990). "Emotional Intelligence". Imagination, Cognition and Personality, 9, 185-211.

[51] Schutte et al. (1998). Development and Validation of a Measure of Emotional Intelligence". Personality and Individual Differences,

[52] Schwarzer, R., \& Jerusalem, M. (1995). Generalized Self-Efficacy scale. In J. Weinman, S. Wright, \& M. Johnston, Measures in health psychology: A user's portfolio. Causal and control beliefs (pp. 35- 37). Windsor, England: NFER-NELSON.

[53] Schwarzer, R \& Hallum, S. (2008). Perceived teacher as selfefficacy as predictor of job stress and burnout: Mediation analyses. Applied Psychology, v 57, p 152-171. Retrieved July 31, 2009. http://www3.interscience.wiley.com

[54] Schwarzer, R., \& Hallum, S. (2008, July 2). Perceived Teacher Self-Efficacy as a Predictor of Job Stress and Burnout: Mediation Analyses. Applied Psychology: An International Review, 57, 152171. Retrieved July 31, 2009, doi:10.1111/j.14640597.2008.00359.x

[55] Selye, H. The Stress of Life. New York: McGrawHill, 1956. Rev. ed. 1976.

[56] Sorcienelli and Gregory. (1987). "Teachers Stress: The Tension Between Career Demands and Having It All”. In: P. Seldon (Ed.) Coping with Teacher Stress, San Francisco: Jossey-Bass.

[57] Sutton, R. E. \& Wheatley, K. F. (2003). Teachers' emotions and teaching: A review of the literature and directions for future research. Educational Psychology Review, 15(4), 327-358.

[58] Travers, C. (2017). Current knowledge on the nature, prevalence, sources and potential impact of teacher stress. Educator Stress, 23-54.
[59] Troesch, L. M., \& Bauer, C. E. (2017). Second career teachers: Job satisfaction, job stress, and the role of self-efficacy. Teaching and Teacher Education, 67, 389-398.

[60] Tschanhen-Moran and Woolfolk. (2001). "Teacher Efficacy: Capturing an Elusive Construct". Teaching and Teacher Education,

[61] Udayar, S., Fiori, M., \& Bausseron, E. (2020). Emotional intelligence and performance in a stressful task: The mediating role of self-efficacy. Personality and Individual Differences, 156, 109790.

[62] Vaezi, S., \& Fallah, N. (2011). The relationship between selfefficacy and stress among Iranian EFL teachers. Journal of Language Teaching and Research, 2(5), 1168-1174.

[63] What is AQ. Retrieved July 31, 2009. http://www.peaklearning.com

[64] Winfield. (2000). Stress in Academic: Some Recent Research Findings". In D.T. Kenny, J.G. Cardson, F.G. McGuigan \& J.L. Shepard (Eds.).

[65] Yodsakun, A \& Kuha, a. (2008 ). Relationship between emotional intelligence (EQ), adversity quotient $(A Q)$ and moral quotient) towards academic achievement of Mattayom Suksa two students. Retrieved July 31, 2009, from http://educms.pn.psu.ac.th/

[66] Zahit, R. (n.d.) Teacher stress: an examination of factors influencing teaching performance in rural elementary schools. Retrieved July 30, 2009 from http://109.cgpublisher.com 


\section{APPENDIX A}

\section{GENERALIZED PERCEIVED SELF-EFFICACY SCALE (GPSS)}

For each question below, place the number that represents your answer in the space provided (1) not at all true, (2) barely true, (3) moderately true, (4) exactly true

1. I can always manage to solve difficult problems if I try hard enough.

2. If someone opposes me, I can find the ways and means to get what I want.

3. I am certain that I can accomplish my goals.

4. I am confident that I could deal efficiently with unexpected events.

5. Thanks to my resourcefulness, I can handle unforeseen situations.

6. I can solve most problems if I invest the necessary effort.

7. I can remain calm when facing difficulties because I can rely on my coping abilities.

8. When I am confronted with a problem, I can find several solutions.

9. If I am in trouble, I can think of a good solution.

10. I can handle whatever comes my way. 


\section{APPENDIX B}

\section{OCCUPATIONAL STRESS SCALE (OSS)}

For each question below, place the number that represents your answer in the space provided

$$
\begin{aligned}
& 1=\text { never } \\
& 2=\text { seldom } \\
& 3=\text { sometimes } \\
& 4=\text { frequently } \\
& 5=\text { nearly all the time }
\end{aligned}
$$

1. How often do you feel that you have too little authority to carry out your responsibilities?

2. How often do you feel unclear about just what the scope and responsibilities of your job are?

3. How often do you not know what opportunities for advancement or promotion exist for you?

4. How often do you feel that you have too heavy a workload, one that you could not possible finish during an ordinary workday?

5. How often do you think that you will not be able to satisfy the conflicting demands of various people around you?

6. How often do you feel that you are not fully qualified to handle your job?

7. How often do you not know what your superior thinks of you, how he or she evaluates your performance?

8. How often do you find yourself unable to get information needed to carry out your job?

9. How often do you worry about decisions that affect the lives of people you know?

10. How often do you feel that you may not be liked and accepted by people at work?

11. How often do you feel unable to influence your immediate supervisor's decisions and actions that affect you?

12. How often do you not know just what the people you work with expect of you?

13. How often do you think that the amount of work you have to do may interfere with how well it is done?

14. How often do you feel that you have to do things on the job that are against your better judgment?

15. How often do you feel that your job interferes with your family life 